\title{
EVALUATION OF BUNDLE BRANCH BLOCKS AND THEIR PROGNOSIS WITH SPECIAL REFERENCE TO HV-INTERVAL
}

\author{
Saroj Mandal1, Debasmita Mandal2, Sudip Kumar Das ${ }^{3}$, Azizul Haque ${ }^{4}$, Sukumar Ghosh ${ }^{5}$, B. Mazumdar6, Pritam Chatterjee ${ }^{7}$ \\ ${ }^{1}$ Assistant Professor, Department of Cardiology, IPGMER \& SSKM Hospital, Kolkata, West Bengal. \\ ${ }^{2}$ Associate Professor, Department of Gynaecology \& Obstetrics, ESI PGIMSR, ESIC Medical College, Joka, West Bengal. \\ ${ }^{3}$ Associate Professor, Department of ENT, BSMC \& H, Bankura, West Bengal. \\ 4 Professor \& HOD, Department OF Cardiology, CNMC \& H, West Bengal. \\ ${ }_{5}^{5}$ Associate Professor, Department OF Cardiology, CNMC \& H, West Bengal. \\ ${ }^{6}$ Professor \& HOD, Department OF Cardiology, BMC \& H, West Bengal. \\ ${ }^{7}$ Senior Resident, Department of ENT, BSMC \& H, Bankura, West Bengal.
}

\section{ABSTRACT}

\section{BACKGROUND}

Patients with chronic bifascicular block (BFB) can progress to advanced atrioventricular block (AVB), especially when syncope or a prolonged HV interval is present.

\section{MATERIALS AND METHODS}

We prospectively studied 100 consecutive BFB patients at a single centre between 2009 and 2012 presenting with syncope or presyncope, who have undergone electrophysiological study. Clinical, electrocardiographic, and electrophysiological variables were analysed to identify the risk of progression to significant AVB (i.e., second or third grade).

\section{RESULTS}

In total, the study included 100 patients (mean age 68.4 years; 20 female). After a follow-up period of 3 years, overall about one half of our patients received pacemaker therapy either in view of markedly prolonged HVI or because of the suggestive symptoms in the face of moderately or severely prolonged HVI. The patients who developed infra-His block during HV-interval study and also who developed stressed HV-interval >65 msec during rapid atrial pacing also treated with permanent pacemaker.

\section{CONCLUSION}

Invasive EPS is safe and effective method for the assessment of progression to advanced AV block. Rate of progression to CHB in patients with normal HV interval is low but cannot be ruled out.

\section{KEYWORDS}

Bundle Branch Block, HV-Interval, Syncope, Pre-Syncope, Electrophysiological Study, Dizziness.

HOW TO CITE THIS ARTICLE: Mandal S, Mandal D, Das SK, et al. Evaluation of bundle branch blocks and their prognosis with special reference to HV-Interval. J. Evolution Med. Dent. Sci. 2016;5(104):7649-7653, DOI: 10.14260/jemds/2016/1725

\section{BACKGROUND}

Chronic bifascicular block (BFB) defined as left bundle branch block (LBBB) or right bundle branch block (RBBB) associated either with a left anterior fascicular block (LAFB) or left posterior fascicular block (LPFB). The estimated prevalence in an adult non-selected population is $1-1.5 \% 1$ and the mortality rate ranges $2-14 \%{ }^{2}$ The incidence of progression of complete heart block varies from $2 \%$ to $6 \%$ a year. BFB has been detected in $7 \%$ of patients admitted with syncope in emergency wards. ${ }^{3}$ Sudden death in patients with bifascicular block may not be caused by the development of complete trifascicular block but rather the presence of ventricular tachyarrhythmia. 1,2

Most of the invasive electrophysiological studies (EPS) performed on patients with BFB have included patients with

Financial or Other, Competing Interest: None.

Submission 07-12-2016, Peer Review 19-12-2016,

Acceptance 22-12-2016, Published 29-12-2016.

Corresponding Author:

Dr. Saroj Mandal,

Assistant Professor

Department of Cardiology,

IPGMER \& SSKM Hospital, Kolkata,

West Bengal, India.

E-mail:drsarojkumarr@gmail.com

DOI: $10.14260 /$ jemds/2016/1725 unexplained syncope (those with no documented arrhythmias on long term monitoring or other noninvasive testing). HV interval (HVI) in patients with BFB is a measure of the conduction time through the remaining functioning fascicle and predicts subsequent development of AV block. Patients with BFB and a prolonged HVI ( $>55 \mathrm{msec}$ ) have $2 \%$ to $3 \%$ risk of developing trifascicular block annually. ${ }^{4}$ The risk is significantly higher if the HVI exceeds $100 \mathrm{msec}$. The rate of progression is low in the absence of an acute intervening event (Drugs, electrolyte abnormalities or ischaemia). The HVI has a high specificity (80\%) but a low sensitivity $(66 \%)$ for predicting development of complete trifascicular block.5,6

Observational data indicates a significantly high prevalence of conduction system abnormalities mainly in the form of complete heart block and fascicular blocks in patients with BFB. There is role of the use of invasive EPS only for the evaluation of syncope in patients having bifascicular block. There is some guidelines regarding the management of patients with symptomatic BFB. Strict adherence to these guidelines may not be always feasible and deviation can occur in special circumstances like where there is doubtful syncope or presyncope and/or loss of consciousness. This is so because we have poor peripheral health care infrastructure, transfer delays to the tertiary care centres and also lack of health awareness among the public. 
The purpose of the present study is to describe the clinical characteristics and outcome of patients with BFB undergoing an electrophysiological study (EPS), to know if elective electrophysiological studies in patients with chronic BFB irrespective of the symptoms would help in the management of these patients and also help to identify the high risk group. The protocol will include assessment of the $\mathrm{AH}$ (Conduction time from the low right atrium through the AV node to the His bundle) and HV (Conduction time from the proximal His bundle to the ventricular myocardium) intervals.

The American College of Cardiology, the American Heart Association, and the North American Society of Pacing and Electrophysiology recommendations for Electrophysiological Studies in patients with Bifascicular block classification are

Class I- Symptomatic patients in whom the cause of symptoms is not known.

Class II- Asymptomatic patients with bundle branch block in whom pharmacological therapy that could increase conduction delay or produce heart block is contemplated.

Class III- (i) Asymptomatic patients with intraventricular conduction delay, (ii) Symptomatic patients whose symptoms can be correlated with or excluded by ECG events.

We believe our study accurately represents the current characteristics and clinical outcomes of patients with BFB, especially those who are symptomatic for syncope or presyncope.

\section{MATERIALS \& METHODS}

\section{Study Area}

Carried out in Department of Cardiology, ICVS, @ IPGMER \& SSKM Hospital, Kolkata-20.

\section{Study Population}

All patients attending Cardiology Department OPD of ICVS, @ IPGMER \& SSKM Hospital, Kolkata-20.

\section{Study Period}

3 Years (October 2009-September 2012)

\section{Sample Size}

All patients with Fascicular Block symptomatic or asymptomatic. No. of patients included in present study were 100.

\section{Inclusion Criteria}

- All patients presented with Fascicular Block and syncope.

- $\quad$ All patients with asymptomatic Fascicular Block.

\section{Exclusion Criteria}

- Patients with Complete Heart Block.

- Patients with Tachyarrhythmia.

Sample Design- To study the patients of Fascicular Block.

Study Design- Non-randomised study.

\section{Parameter to be Studied}

1. To study the patients in terms of detailed history regarding definite syncopal attack and presyncopal attack.

2. To examine clinically to any structural cardiovascular disease.

3. To study the HV-interval in both symptomatic and asymptomatic Bifascicular Block.

\section{Study Tools}

I. History taking and clinical examination.

II. Investigational.

a. Electrophysiological study to measure HV-interval.

b. His electrogram- To obtain a His electrogram, first the catheter is advanced in to RV across the anterior septal portion of the TV, then with gentle clockwise torque, the catheter is withdrawn to straddle the TV.

A high-frequency sharp deflection that precedes ventricular activation and follows septal atrial activation represents a His or proximal right bundle potential.

The HV interval is measured from the $\mathrm{H}$ deflection on the His electrogram to the earliest ventricular activity in any lead.

\section{Study Technique}

This is a comparative study among the members of the study population.

\section{Plan for Analysis of Data}

Data will be presented in the form of tables and charts. Data collected will be plotted and tabulated to correlate and compare the outcome of the study.

\section{RESULTS}

We prospectively studied 100 consecutive BFB patients at a single centre between 2009 and 2012 presenting with syncope or pre-syncope, all of whom had undergone electrophysiological study. Clinical, electrocardiographic, and electrophysiological variables were analysed to identify the risk of progression to significant AVB (i.e, second or third grade). In total, the study included 100 patients, 20 of which were female.

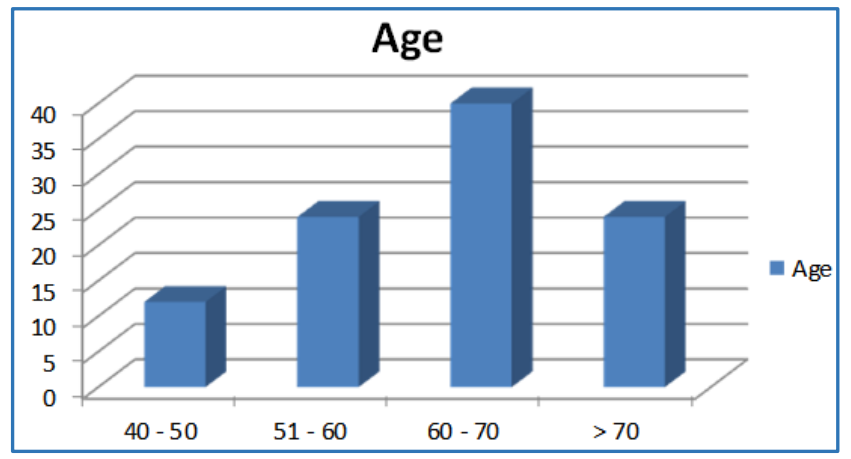

Table 1. Bar Chart of Age Distribution

\begin{tabular}{|c|c|c|}
\hline Sex & No. of Patients (n=50) & Percentage (\%) \\
\hline Male & 80 & 80 \\
\hline Female & 20 & 20 \\
\hline Total & $\mathbf{1 1 0}$ & $\mathbf{1 0 0}$ \\
\hline \multicolumn{2}{|c|}{ Table 2. Sex Distribution $(\mathbf{N = 5 0 )}$} \\
\hline
\end{tabular}




\begin{tabular}{|c|c|c|}
\hline Symptoms & No. of PTS (n=100) & Percentage (\%) \\
\hline Syncope & 72 & 72 \\
\hline Presyncope & 24 & 24 \\
\hline Giddiness & 4 & 4 \\
\hline
\end{tabular}

Table 3. Presenting Symptoms at the time of Admission

\begin{tabular}{|c|c|c|}
\hline $\begin{array}{c}\text { ECG } \\
\text { Patterns }\end{array}$ & $\begin{array}{c}\text { No. of Patients } \\
(\mathbf{n = 1 0 0 )}\end{array}$ & $\begin{array}{c}\text { Percentage } \\
(\mathbf{\%})\end{array}$ \\
\hline CLBBB & 20 & 20 \\
\hline CRBBB+LAHB & 68 & 68 \\
\hline CRBBB+LPHB & 12 & 12 \\
\hline Total & $\mathbf{1 0 0}$ & $\mathbf{1 0 0}$ \\
\hline \multicolumn{2}{|c|}{$\begin{array}{c}\text { Table 4. Different ECG Pattern } \\
\text { before HV-Interval Studies }\end{array}$} \\
\hline
\end{tabular}

\begin{tabular}{|c|c|c|}
\hline $\begin{array}{c}\text { HV Interval } \\
\text { (msec.) }\end{array}$ & $\begin{array}{c}\text { No. of Patients } \\
\text { (n=50) }\end{array}$ & $\begin{array}{c}\text { Percentage } \\
(\mathbf{1 0 0} \%)\end{array}$ \\
\hline$<55$ & 26 & 26 \\
\hline $55-70$ & 48 & 48 \\
\hline $70-100$ & 24 & 24 \\
\hline$>100$ & 2 & 2 \\
\hline \multicolumn{2}{|c|}{ Table 5. Result of EP Study in terms of HV-Interval } \\
\hline
\end{tabular}

\begin{tabular}{|c|ll|l|}
\hline & \multicolumn{2}{|c|}{ Gender } & Mean \\
\hline \multirow{2}{*}{ HV-Interval } & Male & 80 & 62.15 \\
& Female & 20 & 61.30 \\
\hline Stressed & Male & 44 & 60.14 \\
HV-Interval & Female & 16 & 60.25 \\
\hline \multicolumn{2}{|r|}{ Table 6. Mean HV-Intervals and Stressed } \\
\multicolumn{2}{|r|}{ HV-Intervals in Male \& Female Populations } \\
\hline
\end{tabular}

\begin{tabular}{|c|c|c|}
\hline Type of BBB & HVI <65 m sec. & HVI >65 m sec. \\
\hline a) CLBBB & 7 & 3 \\
\hline b) CRBBB+LAHB & 21 & 13 \\
\hline c) CRBBB+LPHB & 4 & 2 \\
\hline \multicolumn{2}{|c|}{ Table 7. Type of Bundle Branch Block and } \\
their Relation with Measured HV-Interval \\
\hline
\end{tabular}

\begin{tabular}{|c|c|c|c|}
\hline $\begin{array}{c}\text { Age } \\
\text { Group (Yrs.) }\end{array}$ & $\begin{array}{c}\text { HVI }< \\
\mathbf{6 5} \mathbf{~ m ~ s e c}\end{array}$ & $\begin{array}{c}\text { HVI > } \\
\mathbf{6 5} \mathbf{~ m ~ s e c ~}\end{array}$ & Total \\
\hline a) $40-50$ yrs. & 3 & 3 & 6 \\
\hline b) $51-60$ yrs. & 8 & 4 & 12 \\
\hline c) $61-70$ yrs. & 14 & 6 & 20 \\
\hline d) $>70$ yrs. & 7 & 5 & 12 \\
\hline Total & $\mathbf{3 2}$ & $\mathbf{1 8}$ & $\mathbf{5 0}$ \\
\hline Table 8. Results of HV Interval in Relation to Age Group \\
\hline
\end{tabular}

\section{Statistical Analysis}

Hundred consecutive patients ( 80 male and 20 female) were enrolled in this study. These comprised of 20 patients with LBBB, 68 with RBBB and LAHB and 12 patients with RBBB and LPHB. The demographic profile and other baseline characteristics of the study population is shown in different tables.

The youngest patient in our series was of 40 years old but the majority were more than 60 years of age and was between 61-70 years group, the total no. of patients in that group was 40 and it was $40 \%$ of total no. of patients. About three-fourths of our patients had symptoms which could be possibly attributed to the presence of BFB at the time of presentation. History of syncope, presyncope or giddiness was recorded in $72 \%, 24 \%$ and $4 \%$ patients respectively. Overall patients with RBBB and LAHB were found to be more often symptomatic than those with other forms of BFB (table 3) these may be related to large number in these groups.

10 patients in our study presented without any definite history of syncope. 36 patients (36\%) had one episode, also other 36 patients had 2 episodes of syncope and only two patients had history of 4 episodes of syncope. In our analysis of patients in relation to BBB, $70 \%$ of male patients had cRBBB+LAHB which $56 \%$ of total patients and in males the least common type of BBB was CRBBB+LAHB, the same type of ECG patterns observed in female population. Table 4 showing measured HV-interval from $<55$ msec to 106 msec and maximum no. of patients had HV-interval that was between 55-70 msec and total no. of patients in this group was 48 (48\%), only one had HV-interval 106 msec. The mean baseline HVI was in males was $62.15 \mathrm{msec}$ and in females was $61.30 \mathrm{msec}$ (Range 40 to $104 \mathrm{msec}$ ). HVI measurement after stressing the His bundle by rapid atrial pacing was done in 64 patients. The decision about pacemaker therapy depended on the recorded HVI (Baseline or post-stress). Therefore, subsequent references to HVI were made to the average highest recorded value. Thus, the average maximum recorded HVI in our patients was $80.00 \pm 23.67 \mathrm{msec}$ (Range 40 to 104 msec) with some of the patients having prolonged HVI $(75.5$ msec). However, the prevalence of prolonged HVI decreased significantly as the cut-off for prolonged HVI was raised from $55 \mathrm{msec}$ value. Only two patients in our study population were found to have markedly prolonged ( $>100 \mathrm{msec}$ ) HVI. Patients of BFB who have attributable symptoms especially syncope often have moderately or severely prolonged HVI and treated with Pacemaker implantation as per standard guideline protocol.

Overall $36(36 \%)$ of our patients received pacemaker therapy. $16(16 \%)$ had an event of syncope over a median followup period of 8 months. After initial evaluation, a total of $36(46 \%)$ patients underwent permanent pacemaker implantation -36 patients for the reason of prolonged HVI in the presence of suggestive symptoms and 8 patients in view of the development of advanced AV block or complete heart block at the time of initial invasive study. Out of the remaining 56 patients who were put on followup, they developed cardiac syncope at 13- and 16-month followup. In the remaining 40 patients, the average followup duration was $10.58 \pm 6.12$ months ranging from 4 to 36 months. None of these patients had any event during the period of followup. There was no difference in outcome with respect to any particular type of BFB. There were no significant complications associated with EPS in our study. No patient developed groin haematoma and one patient developed deep vein thrombosis.

\section{DISCUSSION}

The present study was conducted to evaluate clinical and electrophysiological characteristics of patients with cardiac conduction defects in this part of the country where the prevalence of heart blocks is relatively high. The youngest patient in our series was 40 years old but the majority were more than 60 years of age. Hypertension, diabetes mellitus and coronary heart disease (CHD) were associated in nearly half of the patients with BFB. About three quarters of our patients with BFB had attributable symptoms at the time of 
initial presentation. Syncope of cardiac description was the single most common symptom of BFB present in $43 \%$ patients. Patients with RBBB with LAHB significantly more often reported symptoms, especially syncope, compared to the patients with other forms of BFB.

Available literature reveals that the symptom of greatest concern in BFB is syncope since it is highly predictive of impending high grade AV block and may be present in up to $25 \%$ of the patients first seen with $\mathrm{BFB}^{\left[{ }_{3}\right]}$ The higher prevalence of syncope in our patients with BFB might be due to more advanced conduction disorder since nearly half of them actually presented for the evaluation of cardiac symptoms.

Overall, $88 \%$ of our patients with BFB had prolonged HVI although the prevalence of prolonged HVI decreased significantly as the cut-off for the definition of prolonged HVI was raised from the $55 \mathrm{msec}$ value with less than one-fourth of the patients having markedly prolonged ( $>100 \mathrm{msec}$ ) HVI. The frequency of prolonged HVI in BFB reported by previous observers has been variable ranging from $28 \%$ to $77 \%$. The reason for higher prevalence of prolonged HVI in our series is not clear. It is possible that our patients presented at a later stage in the evolution of the conduction disturbance and accordingly had higher HVI. In our study, QRS duration was found to correlate with HVI in BBB patients.

None of the electrophysiological parameters other than HVI correlated with the final outcome. Overall about one half of our patients received pacemaker therapy either in view of markedly prolonged HVI or because of the suggestive symptoms in the face of moderately or severely prolonged HVI. The patients who developed infra-His block during HVinterval study and also who developed stressed HV-interval > 65 msec during rapid atrial pacing also treated with permanent pacemaker.

Twidale et al in their electrophysiological study performed in 93 patients with bifascicular block and unexplained syncope. Clinical evidence of organic heart disease was present in 33 (35\%). Electrophysiological abnormalities were detected in 85 patients (48\%). Of these, 70 had distal conduction disease, including 56 with an HV interval greater than 55 msec (Mean $76.4 \mathrm{msec}$ ), and eight who developed infra-His block following either intravenous procainamide (Four) or atrial pacing (Four). In our present study, we had excluded organic heart disease though ten patients had prior history of PTCA \& stenting, all of them had preserved left ventricular systolic function. Other parameters positive HV-interval and development of infra-His block were same like our present study.

Nazir A Lone et al $^{6}$ reported in their $88 \%$ of their patients with BFB had prolonged HVI although the prevalence of prolonged HVI decreased significantly as the cut-off for the definition of prolonged HVI was raised from the $55 \mathrm{msec}$ value with less than one-fourth of the patients having markedly prolonged (>100 msec) HVI. The frequency of prolonged HVI in BFB reported by previous observers has been variable ranging from $28 \%$ to $77 \%$. In our present study, we found $36 \%$ of patients with Bundle Branch Block had HV-interval $>65 \mathrm{msec}$.

Pablo et al $^{7}$ performed Electrophysiology studies in 119 adults with chronic bifascicular block manifested by right bundle branch block and left anterior hemi-block. The HVinterval was normal in 86 patients and prolonged in 33 . The following differences in the electrocardiographic and EP findings were found: Patients with a prolonged HV interval had a longer mean P-R interval, QRS duration and AH interval $(\mathrm{P}<0.02)$. In our present study, though positive HV-interval was corroborative with previous study we found $\mathrm{AH}$ interval to be normal and also mean PR interval was not longer.

On final analysis, syncope was the only symptom which significantly predicted the implantation of a pacemaker. The other reported symptoms like presyncope or giddiness did not predict pacemaker treatment. Absence of symptoms was significantly associated with benign outcome in around 90\% of the patients. This finding is consistent with the available literature.

Four of our patients developed infra-His block during measurement of HV-interval. Eight patients with positive stressed HV-interval treated with permanent pacemaker therapy. Nazir A et al reported four of their patients developed complete AV block during EPS, the block was irreversible necessitating implantation of a permanent pacemaker. Injury during right heart catheterisation to the superficially located RBB might induce conduction abnormalities and can produce complete heart block in patients with pre-existing $\mathrm{LBBB}^{7}$ Injury during right heart catheterisation to the superficially located RBB might induce conduction abnormalities and can produce complete heart block in patients with pre-existing LBBB. 8,9 This could be the possible explanation in their patients as they mentioned in their study. We have not come across any complete heart block during our study.

Presence of prolonged PR interval on surface ECG predicted a higher average HVI in patients with BFB reported in previous studies. In our present study, we have not experienced such.

Nazir A Lone et al in their study reported two patients developed groin haematoma and one patient got deep vein thrombosis. But in our study, there were no such complications associated with EP study.

\section{CONCLUSION}

We conclude that BFB commonly affects middle aged and elderly persons and invasive EPS is a safe and effective method for the assessment of progression to advanced AV block. Rate of progression to CHB in patients with normal HV interval is low during this relatively short follow-up period but cannot be ruled out. We propose that even with normal HV interval invasive electrophysiological study (EPS) in symptomatic BFB, patients need close surveillance and regular followup. $\mathrm{HV}$ interval cannot be an absolute determinant factor for decision making of implantation of a permanent pacemaker.

\section{REFERENCES}

1. Rosenbaum MB, Elizari MV, Lazzari J, et al Intraventricular trifascicular blocks. Review of the literature and classification. Am Heart J 1969;78(4):4509.

2. Mirvis DM, Goldberger AL. Electrocardiography. In: Braunwald zipes libby, heart disease. $6^{\text {th }}$ edn. A textbook of cardiovascular medicine 2001:100-5.

3. Englund A, Bergfeldt L, Rehnqvist N, et al. Diagnostic value of programmed ventricular stimulation in patients with bifascicular block: a prospective study of patients 
with and without syncope. J Am Coll Cardiol 1995;26(6):1508-15.

4. Rotman M, Triebunasser JH. A clinical and follow up study of right and left bundle branch block. Circulation 1995;51(3):477-84.

5. Dhingra RC, Palileo E, Strasberg B, et al. Significance of the HV interval in 517 patients with chronic bifascicular block. Circulation 1981;64(6):1265-71.

6. Lone NA, Khan KA, Kumar D, et al. Clinical profile \& outcome in patients with bifascicular block: the role of invasive electrophysiologic study in planning treatment. Jornal of Chinese Clinical Medicine 2010;5(1):19-25.
7. Denes $\mathrm{P}$, Dhingra RC, $\mathrm{Wu} \mathrm{D}$, et al. $\mathrm{H}-\mathrm{V}$ interval in patients with bifascicular block (right bundle branch block and left anterior hemiblock). Clinical, electrocardiographic and electrophysiologic correlations. Am J Cardiol 1975;35(1):23-9.

8. Schneider JF, Thomas HE, Kreger BE, et al. Newly acquired left bundle branch block: the Framingham study. Ann Intern Med 1979;90(3):303-10.

9. Schneider JF, Thomas HE, Kreger BE, et al. Newly acquired right bundle branch block: the Framingham Study. Ann Intern Med 1980;92(1):37-44. 